\title{
Erratum to: Anisotropy and Stress Dependence of Permeability in the Barnett Shale
}

\author{
Athma R. Bhandari ${ }^{1}$ - Peter B. Flemings ${ }^{2}$. \\ Peter J. Polito ${ }^{1}$ - Michael B. Cronin ${ }^{2}$ - Steven L. Bryant ${ }^{3}$
}

Published online: 12 May 2015

C Springer Science+Business Media Dordrecht 2015

\section{Erratum to: Transp Porous Med DOI 10.1007/s11242-015-0482-0}

The following correction to be made to Table 2 in the original paper. The calcite content of sample 2 should be $12.9 \%$ instead of $7.0 \%$.

Table 2 Summary of XRPD analyses

\begin{tabular}{llllllllll}
\hline Sample & \multicolumn{1}{l}{ Minerals } & \multicolumn{1}{l}{$l$} & & & \\
\cline { 2 - 9 } & $\begin{array}{l}\text { Quartz } \\
(\%)\end{array}$ & $\begin{array}{l}\text { Plagioclase } \\
(\%)\end{array}$ & $\begin{array}{l}\text { Calcite } \\
(\%)\end{array}$ & $\begin{array}{l}\text { Dolomite } \\
(\%)\end{array}$ & $\begin{array}{l}\text { Pyrite } \\
(\%)\end{array}$ & $\begin{array}{l}\text { Muscovite } \\
(\%)\end{array}$ & $\begin{array}{l}\text { Illite plus illite- } \\
\text { smectite }(\%)\end{array}$ & $\begin{array}{l}\text { Other } \\
(\%)\end{array}$ & $\begin{array}{l}\text { Total } \\
(\%)\end{array}$ \\
\hline 2 & 32.3 & 2.4 & 12.9 & 5.4 & 2.5 & 3.8 & 39.8 & 0.8 & 99.9 \\
6 & 43.1 & 2.9 & 5.4 & 22.7 & 2.0 & 5.7 & 17.1 & 1.1 & 100 \\
\hline
\end{tabular}

Macaulay Scientific Consulting Limited analyzed our samples using standard XRPD methods

The online version of the original article can be found under doi:10.1007/s11242-015-0482-0.

$\bowtie \quad$ Athma R. Bhandari

athma.bhandari@beg.utexas.edu

1 Bureau of Economic Geology, Jackson School of Geosciences, The University of Texas at Austin, Austin, TX, USA

2 Jackson School of Geosciences, The University of Texas at Austin, Austin, TX, USA

3 Schulich School of Engineering, University of Calgary, Calgary, Canada 